\title{
Estrogen metabolite ratio: Is the 2-hydroxyestrone to 16 $\alpha$-hydroxyestrone ratio predictive for breast cancer?
}

This article was published in the following Dove Press journal:

International Journal of Women's Health

8 February 20II

Number of times this article has been viewed

\author{
Nadia Obi' \\ Alina Vrieling ${ }^{2}$ \\ Judith Heinz' \\ Jenny Chang-Claude ${ }^{2}$ \\ 'University Cancer Center Hamburg \\ (UCCH)/Hubertus Wald Tumor \\ Center, University Medical Center \\ Hamburg-Eppendorf, Hamburg, \\ Germany; ${ }^{2}$ Division of Cancer \\ Epidemiology, German Cancer \\ Research Center, Heidelberg, \\ Germany
}

\begin{abstract}
Experimental studies have shown that two main estrogen metabolites hydroxylated by CYP1A1 and CYP1B1 in the breast differentially affect breast cell proliferation and

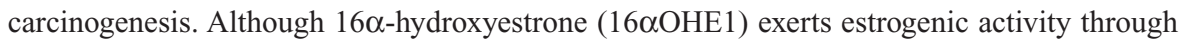
covalent estrogen receptor (ER) binding, 2-hydroxyestrone (2OHE1) presumably has antiestrogenic capabilities. The ratio of 2OHE1 to $16 \alpha \mathrm{OHE} 1$ represents the relative dominance of one pathway over the other and is believed to be modifiable by diet. It was hypothesized that women with or at high risk of breast cancer have a lower estrogen metabolite ratio (EMR) compared with women without breast cancer. We conducted a systematic review on the EMR as a predictor for breast cancer. A total of nine studies (six prospective and three retrospective) matched our inclusion criteria, comprising 682 premenopausal cases (1027 controls) and 1189 postmenopausal cases (1888 controls). For the highest compared with the lowest quantile of urinary EMR, nonsignificant associations suggested at best a weak protective effect in premenopausal but not in postmenopausal breast cancer (range of odds ratios: $0.50-0.75$ for premenopausal and $0.71-1.31$ for postmenopausal). Circulating serum/plasma EMR was not associated with breast cancer risk. Associations were inconclusive for receptor subtypes of breast cancer. Uncontrolled factors known to be involved in breast carcinogenesis, such as 4-hydroxyestrone (4OHE1) concentration, may have confounded results for EMR. Results of the prospective studies do not support the hypothesis that EMR can be used as a predictive marker for breast cancer risk. Future research should concentrate on profiles of estrogen metabolites, including 4OHE1, to gain a more complete picture of the relative importance of single metabolites for breast cancer.
\end{abstract}

Keywords: estrogen metabolite ratio, 2-hydroxyestrone, $16 \alpha$-hydroxyestrone, breast cancer, predictive marker, review

\section{Introduction}

\section{Hypothesis (the extended hormonal risk factor hypothesis)}

It is well known that endogenous estrogens have the potential of inducing and promoting cell proliferation and inducing tumor growth in breast tissue. Circulating estrogen levels correlate with breast cancer risk in postmenopausal women. ${ }^{1,2}$ For premenopausal women, the estrogen-breast cancer association is not as well established. Some evidence for an association was found in one prospective study ${ }^{3}$ but was not statistically significant in five other studies, ${ }^{4}$ probably due to the much higher intra- and interindividual variation through menstrual cycle and reproductive lifetime.,

Since the early 1980s, a growing number of studies examined whether not only native estrogens but also their hydroxylated estrogen metabolites have potential carcinogenic properties in breast tissue. Experimental studies in breast cancer cells 
and animal models established the hypothesis of a differential estrogenic activity of the two main estrogen metabolites, 2-hydroxyestrone (2OHE1) and 16 $\alpha$-hydroxyestrone (16 $\alpha$ OHE1). Because 2OHE1 has a weak binding capacity to the ER and has been associated with normal cell differentiation and apoptosis, ${ }^{7-9}$ it is assumed to have antiestrogenic properties. ${ }^{10}$ In contrast, the other major metabolite, $16 \alpha \mathrm{OHE} 1$, can bind covalently to the ER and has been shown to induce abnormal cell proliferation. ${ }^{11,12}$

Both 2- and 16 $\alpha$-estrogen hydroxylating pathways are mutually exclusive and irreversible. Thus, the metabolite ratio of $2 \mathrm{OHE} 1$ to $16 \alpha \mathrm{OHE} 1$ reflects the relative dominance of one pathway over the other. Since several relatively small-scale observational studies and human breast tissue studies found lower ratio levels accompanied by higher $16 \alpha \mathrm{OHE} 1$ concentrations in breast cancer cases compared with women without breast cancer, ${ }^{13-18}$ it has been suggested that this ratio may be used as a marker for the assessment of breast cancer risk. Subsequent studies yielded inconsistent results as to whether a lower ratio is associated with a higher risk for breast cancer, both in premenopausal and in postmenopausal women.

A concurrent hypothesis postulates that the catecholestrogens 2OHE1/2OH-estradiol and especially the 4-hydroxylated estrogens 4-hydroxyestrone (4OHE1) and 4-hydroxyestradiol may play an important role in breast carcinogenesis because of their ability to induce DNA depurination independent of ER binding. ${ }^{19,20}$ Although experimental studies have demonstrated the carcinogenic potential of $4 \mathrm{OHE} 1,{ }^{21,22}$ little attention has been given to 4OHE1 in epidemiological studies. Therefore, we focus here on the estrogen metabolite ratio (EMR) of $2 \mathrm{OHE} 1$ to $16 \alpha \mathrm{OHE} 1$.

\section{Metabolism of endogenous estrogens, genetic polymorphisms}

In a first step, native 17ß-estradiol (E2) and its oxidized form, estrone (E1), are metabolized to various hydroxylated estrogens by cytochrome P450-dependent pathways. The catecholestrogens 2OHE1/E2 and 4OHE1/E2 are characterized by two neighboring hydroxyl groups, which are rapidly methylated by the enzyme catechol- $O$-methyltransferase (COMT) to form 2-Meth-O-E1/E2 or 4-Meth-O-E1/E2. Further oxidation of unmethylated hydroxyestrogens may generate semiquinones and quinones, which on one hand can function as substrate for redox cycling processes, leading to reactive oxygen species (ROS), and on the other hand can bind to DNA to form stable or depurinating adducts with adenine or guanine. Subsequently, quinones and hydroxylated estrogens, including $16 \alpha \mathrm{OHE} 1$, are sulphatized or glucuronidated before excretion. ${ }^{23}$ The tissue-specific hydroxylases are encoded by CYP1A1, CYP1B1 (breast), and CYP1A2 (liver) for the 2-hydroxylation of E1 to form 2OHE1/E2 and CYP1A1, CYP3A5 (breast), ${ }^{24}$ CYP3A4, and CYP3A $7^{25}$ for $16 \alpha$-hydroxylation. A smaller fraction of estrogens is hydroxylated to 4OHE1/E2 by CYP1B1 (breast) and CYP1A2 (liver) enzymes. ${ }^{22}$ Tissue concentrations of the CYP enzymes vary considerably, and many of them are genetically polymorph, which implicates differences in activity levels of the hydroxylases. ${ }^{26,27}$ Polymorphisms have also been described for COMT, leading to slower methylation of catecholestrogens. ${ }^{28,29}$

\section{Menopausal status}

To date, it is not well established whether the menopausal transition is accompanied by a general shift of the EMR to favor $16 \alpha \mathrm{OHE} 1$, as has been previously discussed. ${ }^{30}$ Although levels of estrogen metabolites are several times higher in premenopausal compared with postmenopausal women, a woman's metabolite ratio seems to be relatively stable throughout her life. ${ }^{31}$ Most of the earlier studies on the EMR reported no significant mean differences between preand postmenopausal control groups without breast cancer. ${ }^{32}$ Because the limited available data do not provide clear indication of an important influence of menopausal status on the EMR, both pre- and postmenopausal women were considered in this review.

The purpose of the present review was to evaluate the evidence for an inverse relation between EMR and breast cancer risk and whether this ratio can potentially serve as a predictive marker.

\section{Methods Selection of studies}

A PubMed/MEDLINE search on epidemiologic studies of estrogen metabolites and breast cancer was conducted up to February 2010. The search strategy consisted of a combination of MeSH terms ("hydroxyestrones" and "breast neoplasms") and key words in titles and abstracts ("estrogen metabolites", "2-hydroxylation", and "breast cancer"). References from resulting articles were screened for missed studies. If only abstracts of publications were available, they were excluded from the review.

\section{Inclusion criteria}

Studies were included in this review if risk estimates and confidence intervals (CIs) of the urinary or circulating EMR 
(2OHE1/16 $\alpha \mathrm{OHE} 1)$ were reported for subjects not taking oral contraceptives, hormones, or tamoxifen and not pregnant at the time of blood donation or urine collection. Further requirements included frequency or individual matching of controls to cases by age and stratification by or adjustment for menopausal status to assess potentially differential evidence for pre- and postmenopausal women.

\section{Measurement of the $2 \mathrm{OHEI} / 16 \alpha \mathrm{OHEI}$ EMR}

All but one study, ${ }^{33}$ which employed an earlier version, used an improved enzyme immunoassay ${ }^{34}$ (ELISA; ESTRAMET, Immunacare Corporation, Bethlehem, PA, USA) developed by Klug et $\mathrm{a}^{35}$ for simultaneous urinary metabolites assessment. The assay measures three of at least 15 metabolites and parent estrogens, ie, 2OHE1, 2-hydroxyestradiol (2OHE2), and $16 \alpha \mathrm{OHE} 1$. Therefore, the EMR reflects the $2 \mathrm{OHE} 1+2 \mathrm{OHE} 2 / 16 \alpha \mathrm{OHE} 1$ ratio. The EMR is independent of urinary creatinine concentration.

\section{Data extraction}

To compare the median/mean EMR across studies, the third quintile's midpoint of EMR in pre- and postmenopausal controls has been derived as an approximate value for Muti et $\mathrm{al}^{36}$ and the numbers in each tertile in the study by Meilahn et $\mathrm{al}^{33}$ were deduced from given percentages. Risk estimates for quantiles and 95\% CIs of the EMR were extracted from the tables of the publications and analyzed. To test for overall heterogeneity and heterogeneity by specimen type (urine, serum/plasma), risk estimates were weighted and pooled, and Cochran's $Q$ statistic $^{37}$ was calculated.

\section{Results}

Overall, 21 studies were identified that dealt with any kind of estrogen metabolites and associated breast cancer risk, of which nine were included in this review (Table 1). One study included only premenopausal women ${ }^{38}$ and four studies only postmenopausal women, ${ }^{39-42}$ and the remaining four studies matched for menopausal status or analyzed data stratified by menopausal status. ${ }^{33,36,43,44}$

\section{Excluded studies}

The main reasons for exclusion were nonavailability of risk estimates, including CIs of the association between EMR and breast cancer, ${ }^{13,14,18,45-51}$ and recruitment of control subjects from convenient samples that were not individually matched to cases by age. . $^{13,14,16-18,45,46,48,51}$ Almost all of these small case-control studies, comprising, in total, 401 cases and
429 controls, found lower mean EMRs in cases compared with controls (Supplementary Table). Kabat et al ${ }^{17}$ reported for a small hospital-based study an extreme risk reduction for the third versus first tertile of urinary EMR in postmenopausal women (adjusted odds ratio [OR]: 0.03, 95\% CI: 0.003-0.29), but not in the combined group of pre- and postmenopausal women (OR: 0.51, 95\% CI: 0.17-1.56). Similarly, Ho et $\mathrm{al}^{16}$ who used controls with biopsies for benign breast disease, found at a urinary EMR median cut-point of 0.9 a strong inverse association independent of menopausal status (OR: 0.16, 95\% CI: 0.05-0.49).

\section{Included studies}

The nine studies included were published between 1998 and 2009. Study characteristics are summarized in Table 1. In total, these studies comprised 682 premenopausal cases and 1027 premenopausal controls (five studies) and 1189 postmenopausal cases and 1888 postmenopausal controls (seven studies). Six studies were nested case-control studies within prospective cohorts, ${ }^{33,36,38,40-42}$ and three were retrospective population-based case-control studies ${ }^{39,43,44}$ with determination of the metabolites after disease onset. Studies were conducted in China, ${ }^{44}$ Italy, ${ }^{36}$ the UK, ${ }^{33}$ Denmark, ${ }^{41}$ and the US. ${ }^{38-40,42,43}$ The baseline age distribution varied naturally across studies according to menopausal status, with the minimum age ranging from 25 years ${ }^{44}$ to 65 years. ${ }^{40}$ All studies were matched for age, and prospective but not retrospective studies in premenopausal women were additionally matched for phase of menstrual cycle at time of specimen sampling (follicular or luteal ${ }^{33,38}$ and only luteal). ${ }^{36}$ Median follow-up time between specimen sampling and diagnosis of breast cancer (approximately equal to time between sampling and laboratory analysis) ranged from 2.4 years in the Danish cohort ${ }^{41}$ to $12-18$ years in one of the US cohorts. ${ }^{38}$ The retrospective studies collected urine prior to any therapy for several months, ${ }^{44}$ a median of 3 months, ${ }^{43}$ or several years ${ }^{39}$ after diagnosis.

Six studies investigated urinary excretion of estrogen metabolites, and three of the more recent studies examined serum/plasma concentrations. ${ }^{38,40,42}$ Among controls, mean urinary EMR values were consistently above 1, whereas means of circulating EMR were all below 1. In Western countries, urinary mean EMR varied between 1.9 and 2.57 in controls, whereas in the Shanghai study by Fowke et $\mathrm{al}^{44}$ the mean EMR was around 50\% lower. A significant difference between preand postmenopausal controls in mean urinary EMR has been found only in the UK cohort. ${ }^{33}$ Studies of serum/plasma EMR examined either pre- or postmenopausal women. 
Table I Characteristics of included studies on EMR and breast cancer risk estimates

\begin{tabular}{|c|c|c|c|c|c|c|}
\hline Authors & Country & Design & Medium & $\begin{array}{l}\text { Age (range and/or } \\
\text { mean (SD)) }\end{array}$ & $\begin{array}{l}\text { Cases/controls } \\
\text { (total) }\end{array}$ & $\begin{array}{l}\text { Cases/controls } \\
\text { (in models) }\end{array}$ \\
\hline \multicolumn{7}{|c|}{ Premenopausal } \\
\hline Meilahn et al ${ }^{33}$ & UK & $\begin{array}{l}\text { Prospective nested } \\
\text { case-control }\end{array}$ & Spot urine & $>34(40.5(4.2))$ & $60 / 184$ & $\begin{array}{l}21 / 62 \\
22 / 61 \\
17 / 61\end{array}$ \\
\hline Muti et al ${ }^{36}$ & Italy & $\begin{array}{l}\text { Prospective nested } \\
\text { case-control }\end{array}$ & I2-h urine & $35-57$ & $67 / 264$ & $\begin{array}{l}19 / 54 \\
14 / 51 \\
11 / 52 \\
12 / 54 \\
11 / 53\end{array}$ \\
\hline Kabat et $\mathrm{a}^{43}$ & USA & $\begin{array}{l}\text { Population-based } \\
\text { case-control }\end{array}$ & Spot urine & $<50->60$ & $105(70$ is $) / / 29$ & $\begin{array}{l}44 / 46 \\
35 / 42 \\
26 / 41\end{array}$ \\
\hline Arslan et $\mathrm{a}^{38}$ & USA & $\begin{array}{l}\text { Prospective, nested } \\
\text { case-control }\end{array}$ & Serum & $\begin{array}{l}35-65 \\
44.3(4.8)\end{array}$ & $377 / 377$ & $\begin{array}{l}\text { Not given for } \\
\text { quartiles }\end{array}$ \\
\hline \multicolumn{7}{|c|}{ Mixed menopausal } \\
\hline $\begin{array}{l}\text { Fowke et al }{ }^{44} \\
\text { (presurgical) }^{\mathrm{a}}\end{array}$ & China & $\begin{array}{l}\text { Population-based } \\
\text { case-control }\end{array}$ & Spot urine & $25-65$ & 78/78 presurgical & $\begin{array}{l}30 / 20 \\
25 / 27 \\
23 / 31\end{array}$ \\
\hline $\begin{array}{l}\text { Fowke et al }{ }^{44} \\
\text { (postsurgical) }^{\mathrm{a}}\end{array}$ & China & $\begin{array}{l}\text { Population-based } \\
\text { case-control }\end{array}$ & Spot urine & $25-65$ & $32 / 32$ postsurgical & $\begin{array}{l}5 / 14 \\
10 / 11 \\
17 / 7\end{array}$ \\
\hline \multicolumn{7}{|c|}{ Postmenopausal } \\
\hline Meilahn et $\mathrm{al}^{33}$ & UK & $\begin{array}{l}\text { Prospective, nested } \\
\text { case-control }\end{array}$ & Spot urine & $\begin{array}{l}>50 \\
59(6.2)\end{array}$ & $42 / 139$ & $\begin{array}{l}15 / 47 \\
16 / 46 \\
13 / 46\end{array}$ \\
\hline Ursin et al ${ }^{39}$ & USA & $\begin{array}{l}\text { Population-based } \\
\text { case-control }\end{array}$ & Spot urine & $50-70$ & $66 / 76$ & $\begin{array}{l}29 / 26 \\
11 / 25 \\
26 / 25\end{array}$ \\
\hline Muti et $\mathrm{al}^{36}$ & Italy & $\begin{array}{l}\text { Prospective, nested } \\
\text { case-control }\end{array}$ & I2-h urine & $43-70$ & $7 I / 274$ & $\begin{array}{l}12 / 54 \\
16 / 55 \\
17 / 54 \\
12 / 57 \\
14 / 54\end{array}$ \\
\hline Wellejus et $\mathrm{al}^{4 !}$ & Denmark & $\begin{array}{l}\text { Prospective, nested } \\
\text { case-control }\end{array}$ & Spot urine & $50-64$ & 197/197 & 197//97 \\
\hline Kabat et $\mathrm{a}^{43}$ & USA & $\begin{array}{l}\text { Population-based } \\
\text { case-control }\end{array}$ & Spot urine & $<50->60$ & $164(88$ is $) / / 97$ & $\begin{array}{l}70 / 64 \\
62 / 52 \\
65 / 48\end{array}$ \\
\hline Cauley et $\mathrm{al}^{40}$ & USA & $\begin{array}{l}\text { Prospective } \\
\text { case-cohort }\end{array}$ & Serum & $\begin{array}{l}70(5) \\
>65\end{array}$ & $272 / 29 \mid$ & $\begin{array}{l}69 / 70 \\
97 / 72 \\
64 / 75 \\
72 / 74\end{array}$ \\
\hline Eliassen ${ }^{42}$ & USA & $\begin{array}{l}\text { Prospective, nested } \\
\text { case-control }\end{array}$ & Plasma & $\begin{array}{l}61.5(4.7) \\
43-69\end{array}$ & $340 / 677$ & $\begin{array}{l}74 / 169 \\
89 / 168 \\
87 / 170 \\
90 / 168\end{array}$ \\
\hline
\end{tabular}




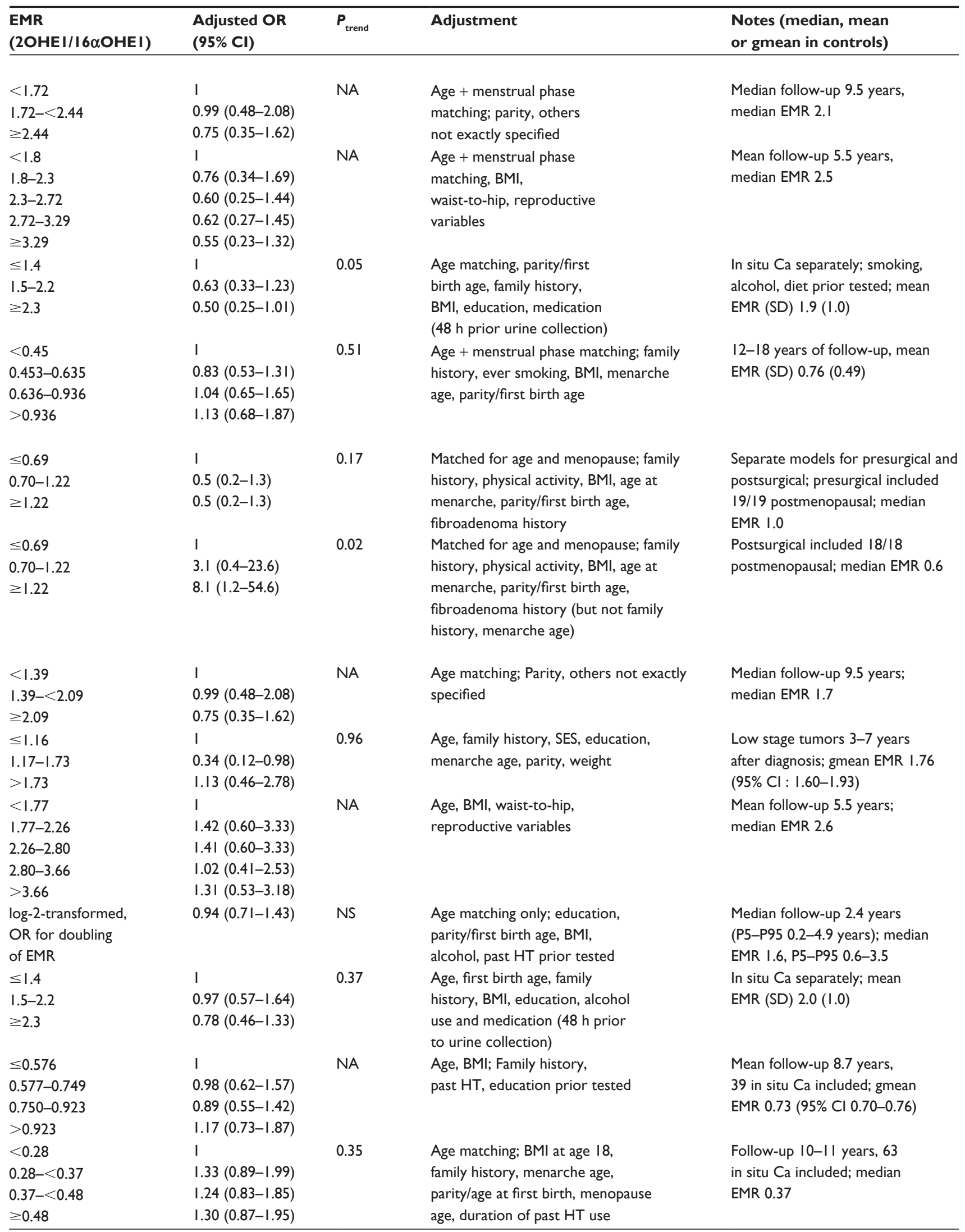

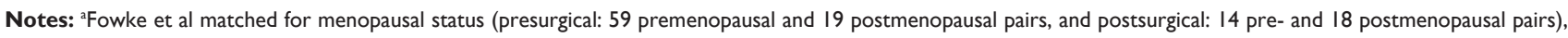
thus estimates refer to both pre- and postmenopausal women.

Abbreviations: $\mathrm{BMI}$, body mass index; $\mathrm{Ca}$, carcinoma; $\mathrm{Cl}$, confidence interval; EMR, estrogen metabolite ratio; gmean, geometric mean; $\mathrm{HT}$, hormone therapy; is, in situ; NA, not available; NS, not significant; P5-P95, 5th percentile to 95th percentile; SD, standard deviation; SE, standard error; SES, socioeconomic status. 
All studies but one ${ }^{41}$ used percentile distributions of the EMR among controls to assess the association with breast cancer risk by comparing the highest with the lowest group (tertiles, quartiles, or quintiles) with conditional or unconditional logistic regression or Cox ${ }^{40}{ }^{40}$ regression analysis. Wellejus et $\mathrm{a}^{41}$ applied log-2-transformed EMR values that reflect a doubling of concentration per unit change. Adjustment for potentially confounding factors differed slightly between studies. Characteristics that were included in most models were age, body mass index (BMI) or waist-to-hip ratio, and reproductive variables known to be risk factors for breast cancer. Wellejus et $\mathrm{al}^{41}$ did not adjust their analysis apart from matching for exact age, and Cauley et $\mathrm{al}^{40}$ adjusted their analysis only for age and BMI. Of the four studies that included both pre- and postmenopausal women, three analyzed pre- and postmenopausal women separately. ${ }^{33,36,43}$
The Shanghai study reported combined estimates based on analyses stratified by menopausal status and time of urine collection relative to surgery/treatment status. ${ }^{44}$

Main study results (risk estimates, 95\% CI) are presented by specimen and menopausal status in Table 1 and Figure 1.

\section{Urinary EMR Premenopausal breast cancer}

In the UK study (60 cases), the EMR was associated with a nonsignificant $25 \%$ risk reduction (first vs third tertile: $\mathrm{OR}=0.75,95 \% \mathrm{CI}=0.35-1.62) .{ }^{33}$ The Italian study ${ }^{36}$ (67 cases) reported nonsignificantly decreased ORs for the second to fifth quintile (ORs: Q2-Q5 = 0.76-0.55). A $50 \%$ risk reduction $(95 \% \mathrm{CI}: 0.25-1.01)$ for the highest tertile of the EMR was found in the retrospective study by

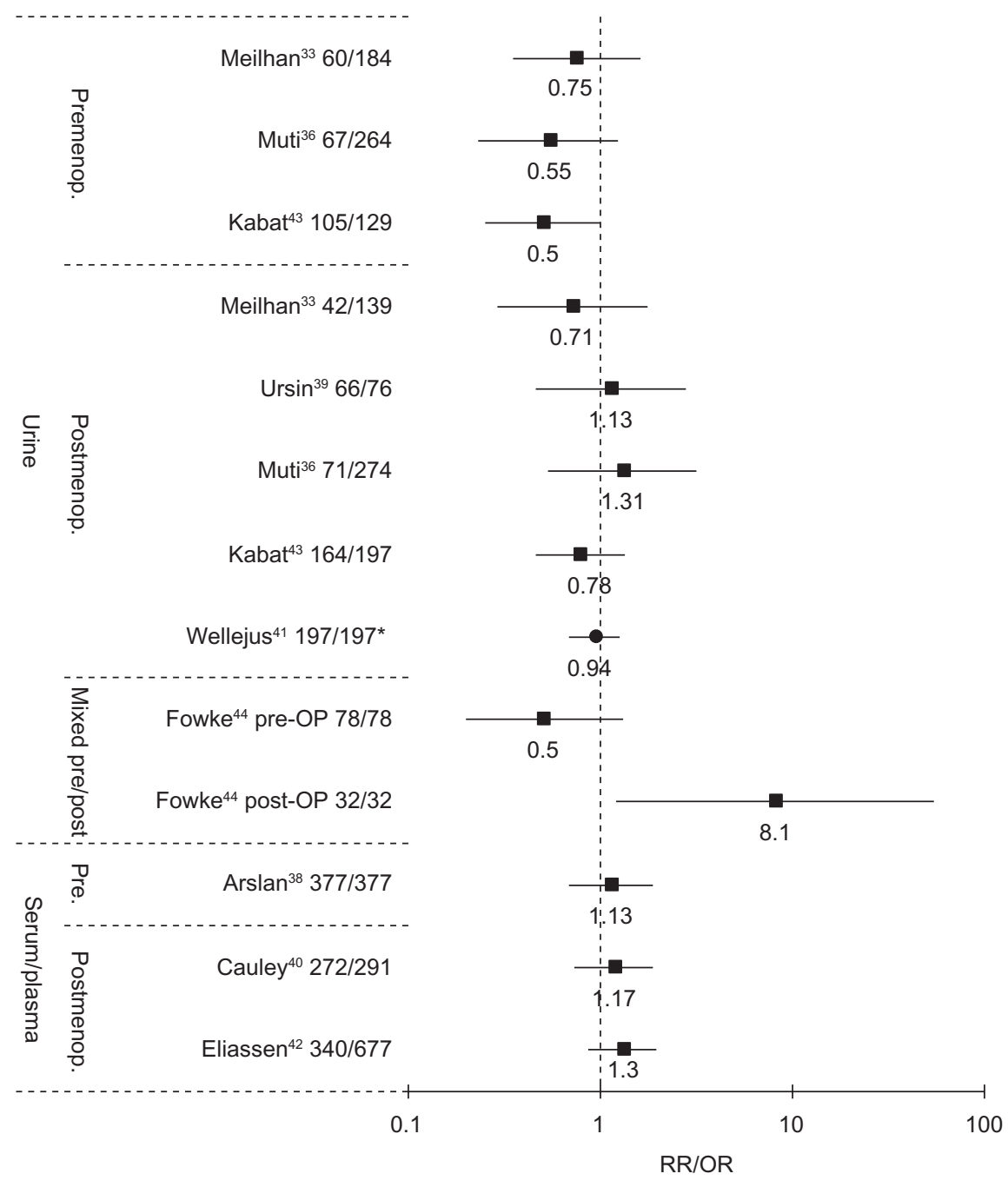

Figure I OR/RR for highest versus lowest quantile of EMR in studies on pre- and postmenopausal breast cancer. Note: Wellejus used log-2-transformed EMR, representing a doubling of EMR per unit increase.

Abbreviations: EMR, estrogen metabolite ratio; OR, odds ratio; RR, risk ratio. 
Kabat et al. ${ }^{43}$ Analysis repeated for cases prior to and after chemotherapy showed no substantial differences in risk estimates. Fowke et $\mathrm{al}^{44}$ reported results for 78 presurgical (the majority being premenopausal) and 32 postsurgical pairs (14 pairs being premenopausal). For presurgical pairs, the tertiles of the EMR were nonsignificantly associated with a $50 \%$ risk reduction, whereas a significantly positive association was present postsurgically (OR for third vs first tertile: 8.1, 95\% CI: 1.2-54.6). Only Kabat et $\mathrm{al}^{43}$ observed an inverse dose-response relationship over tertiles of $\operatorname{EMR}\left(P_{\text {trend }}=0.05\right)$, whereas other studies found no trends ${ }^{38,44}$ or did not provide a trend test. ${ }^{33,36}$

\section{Postmenopausal breast cancer}

Meilahn et $\mathrm{al}^{33}$ (42 cases) and Kabat et $\mathrm{al}^{43}$ (164 cases) reported nonstatistically significant inverse associations for the highest versus lowest tertile of the EMR (respective ORs 0.75 and 0.78 ), whereas Muti et $\mathrm{al}^{36}$ (71 cases) and Ursin et $\mathrm{al}^{39}$ (66 cases) observed nonsignificant risk elevations. Wellejus et $\mathrm{al}^{41}$ found no significant relationship among 197 case-control pairs for a doubling of EMR per increment (OR: 0.94, 95\% CI: 0.71-1.43).

In summary, none of the urinary studies reported a statistically significant inverse association between EMR and breast cancer risk, although the premenopausal study by Kabat et $\mathrm{al}^{43}$ showed an upper confidence limit close to 1 .

\section{Serum/plasma EMR}

\section{Premenopausal breast cancer}

Arslan et $\mathrm{al}^{38}$ found no association between the serum EMR and premenopausal breast cancer risk among 377 case-control pairs, the OR for the top versus bottom quartile being 1.13 (95\% CI: 0.68-1.87). Repeated analyses according to menstrual cycle phase (follicular pairs and luteal pairs) or after excluding cases diagnosed within 5 or 10 years after enrollment did not yield different results.

\section{Postmenopausal breast cancer}

Eliassen et $\mathrm{al}^{42}$ and Cauley et $\mathrm{al}^{40}$ included in situ cases in their analyses of 340 and 272 cases, respectively. Both studies found nonsignificant risk elevations for the highest compared with the lowest quartile of circulating EMR levels. Thus, the serum/plasma EMR was not significantly associated to pre- or postmenopausal breast cancer.

\section{Heterogeneity testing}

The test for heterogeneity across the combined pre- and postmenopausal urinary studies $\left(P_{\text {heterogeneity }}=0.86\right)$ and the test for circulating EMR studies $\left(P_{\text {heterogeneity }}=0.86\right)$ were negative. Additionally, the test for heterogeneity across all nine urinary and circulating EMR studies revealed no significant inconsistency between studies $\left(P_{\text {heterogeneity }}=0.61\right)$.

\section{Breast cancer subtypes: receptor status and in situ cancer}

Kabat et al found the urinary EMR to be statistically, significantly, and inversely related to ER-positive premenopausal tumors (third vs first tertile OR: 0.32, 95\% CI: 0.12-0.84) and nonsignificantly related to ER-negative tumors in postmenopausal women (OR: 0.38, 95\% CI: 0.15-1.01). ${ }^{43}$ A nonsignificant inverse association in ER-negative cases (OR for doubling of urinary EMR: 0.78, 95\% CI: $0.42-1.48$ ) was also reported by Wellejus et al. ${ }^{41}$ In contrast, serum/plasma levels of EMR were increased in ER-negative postmenopausal cases (OR: 3.7, 95\% CI: $\left.1.24-11.09, P_{\text {trend }}=0.004, P_{\text {heterogeneity }}=0.005\right)$ in one study $^{42}$ and in ER-positive premenopausal cases in the other study (OR: 2.15, 95\% CI: 0.88-5.27). ${ }^{38}$ Apart from Eliassen et $\mathrm{al}^{42}$ none of the studies tested for heterogeneity by ER status.

Kabat et $\mathrm{al}^{43}$ separately investigated 70 premenopausal and 88 postmenopausal cases with carcinoma in situ of the breast. No association of EMR was observed in both groups. Likewise, from their overall negative results, Eliassen et $\mathrm{al}^{42}$ reported no differential relationship for postmenopausal in situ breast cancer.

\section{Discussion Summary of main results}

Overall, nine studies that fulfilled our inclusion criteria investigated the association between the EMR of 2- to $16 \alpha$-hydroxyestrone and breast cancer risk, six of which examined urinary and three circulating EMR. Studies on urinary EMR found ORs between 0.50 and 0.75 (except for the postsurgical OR in Fowke et al $)^{44}$ in premenopausal women and between 0.71 and 1.31 in postmenopausal women, comparing the highest with the lowest quantiles or, in one study, a doubling of EMR. Although none of the studies reached statistical significance, the premenopausal arm of the retrospective study by Kabat et al was borderline significant, suggesting that an inverse association of urinary EMR might be confined to premenopausal breast cancer. However, there was no differential effect in all urinary studies combined $\left(P_{\text {heterogeneity }}=0.86\right)$, which contradicts a hypothesized modification by menopausal status. Similarly, the circulating EMR was not associated with breast cancer 
risk in pre- or postmenopausal women (ORs ranging from 1.13 to $1.30, P_{\text {heterogeneity }}=0.86$ ). There was also no significant heterogeneity across all combined urinary and serum/plasma studies $\left(P_{\text {heterogeneity }}=0.61\right)$.

\section{Receptor status and in situ carcinomas}

Limited data on ER status with contradictory results do not allow a firm conclusion regarding heterogeneity in the relationship between EMR and breast cancer risk by ER status. The two studies, which investigated in situ carcinomas separately, did not find the EMR to be inversely associated with risk of in situ breast cancer.

\section{Quality of evidence} Completeness of data

Exclusion of two earlier small studies, ${ }^{16,17}$ which found strong inverse associations for EMR, may have led to certain bias toward null results, but these studies were not included due to flaws in design or reporting. A funnel plot (Figure 2), including these studies, suggested that there might have been publication bias in this early phase. Another larger excluded study that assessed only single estrogen metabolites in serum of postmenopausal hormone therapy nonusers did not report statistically significant associations with breast cancer risk. ${ }^{47}$ Though not necessarily, it is likely that the EMR was also not associated with breast cancer in this study.

\section{Study size and power}

The earliest publications that reported an inverse association between EMR and breast cancer risk were based on small numbers and thus have a tendency to overestimate the effect. Many of the subsequently published studies also had relatively small study sizes ${ }^{33,36,39,44}$ and consequently limited statistical power to detect a significant risk reduction of about 30\% (likely effect magnitude based on the first cohort studies). ${ }^{33,36}$ If tertiles of exposure are considered, at least 200 case-control pairs are needed to identify a $50 \%$ risk reduction and 400 pairs to detect a relative risk of 0.7 with $80 \%$ power at an alpha of $0.05 .^{52}$

\section{Study design}

The studies were heterogeneously designed, including both prospective and retrospective studies, using urinary or circulating EMR measurements for exposure assessment, including diverse populations, and many lacking statistical power. These variations may partly explain the differences in risk estimates for EMR.

The EMR may be influenced by disease status (tumor-driven activity), stage, and treatment. ${ }^{18,43,44,53}$ Thus, the hypothesized association between the EMR and breast cancer might be subject to reverse causation in retrospective case-control studies. Fowke et $\mathrm{al}^{44}$ found a decreased EMR risk in presurgical cases and an increased EMR risk

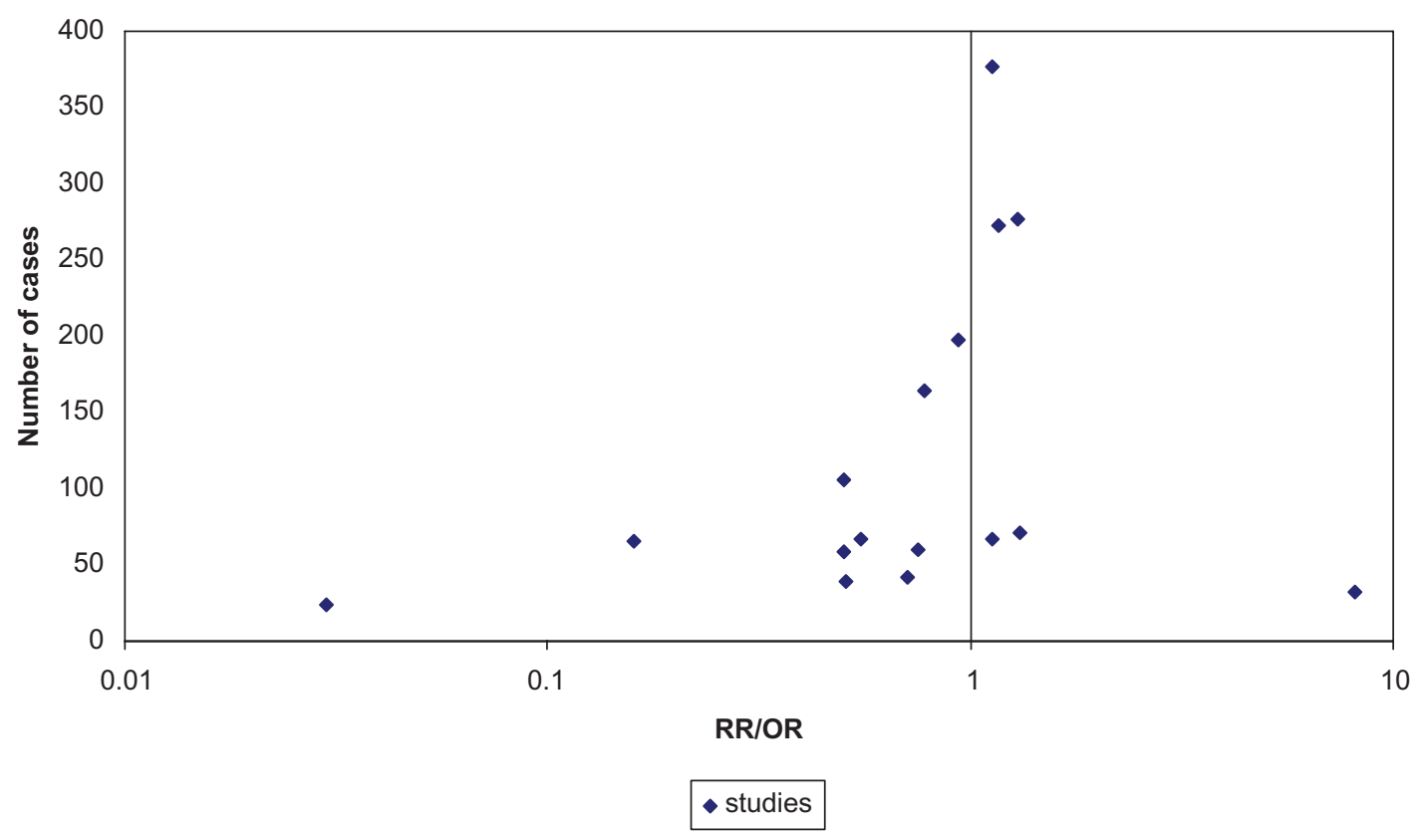

Figure 2 Funnel plot of risk estimates of nine included ${ }^{33,36,38-44}$ and two excluded studies ${ }^{16,17}$ (separate RR/OR for menopausal status, where available). Abbreviations: RR, risk ratio; OR, odds ratio. 
in postsurgical cases. If pre- and postsurgery subgroups were combined, this would have resulted in a crude OR for the EMR of 1.02 (95\% CI: 0.72-1.25). Hence, an existing inverse association may be masked by a potential influence of treatment on EMR. No study actually assessed the intraindividual variability in EMR before and after a breast cancer diagnosis. Therefore, prospective studies of EMR will be required to elucidate a potential association of EMR with breast cancer.

\section{Adjustment for confounders in the individual studies} Only studies that excluded current users of exogenous hormones were included in this review, as oral contraceptives and menopausal hormone therapy have been shown to increase ${ }^{54-57}$ or decrease EMR. ${ }^{41,47}$ Many of the known breast cancer risk factors, such as reproductive variables (ie, parity and age at first birth) and BMI, which have been found to be associated with the EMR, ${ }^{42,58}$ were controlled in most included studies. Menstrual cycle phase in premenopausal women, a family history of breast cancer, and a history of benign breast disease were not consistently adjusted for. Although little evidence indicates that EMR is associated with a family history ${ }^{59}$ or benign breast disease, circulating EMR has been shown to increase during the menstrual cycle. ${ }^{60}$ Urinary estrogen metabolite levels vary strongly by ethnicity, showing lowest mean values in healthy African Americans followed by Asians and Caucasians. 32,45,61-64 Although ethnic variations in plasma EMR were less pronounced, ${ }^{55}$ uncontrolled confounding could have masked, diluted, or even pretended a potential EMR effect in studies not adjusted for ethnicity depending on the combination of case-control pairs (even if percentages [other than for Caucasians] were as low as $12 \%-16 \%) .{ }^{38,43}$ However, in some studies, adjusted risk estimates did not differ substantially from crude estimates, and EMR varied only slightly across categories of covariates. ${ }^{33,36,40,41}$ Therefore, the risk estimates in these studies were considered as appropriate.

\section{Possible modifiers of the association between EMR and breast cancer}

Menopausal status did not strongly affect EMR in most studies, which is compatible with the observed overlapping distributions of EMR in pre- and postmenopausal women. ${ }^{32}$ Genetic makeup and differential activity of metabolizing hydroxylases and other enzymes (eg, COMT) have been estimated to explain most of the variation in EMR. ${ }^{65}$ In addition, estrogen hydroxylation pathways, particularly 2-hydroxylation, are believed to be modifiable through diet, physical activity, smoking, alcohol consumption, and caffeine intake. Clinical trials and observational studies generated inconsistent results regarding a potential influence of diet (eg, soy products, fat/fiber, and Brassica vegetables) and physical activity habits on EMR. Studies in the present review do not support that EMR may be associated with breast cancer risk in specific subgroups.

\section{Reliability of measurements}

Reliability of a single urinary EMR measurement in premenopausal women was rated sufficient in studies on variation in intraindividual EMR during the menstrual cycle. ${ }^{31,66}$ Intraclass correlation coefficients between two urinary EMR measurements were 0.71 over a 1 -year period ${ }^{67}$ and $0.67^{30}$ over a 6-month period, and between two plasma EMR measurements were 0.73 over a 3 -year period. ${ }^{42}$ All included studies, except for the study by Meilahn et al, ${ }^{33}$ used a refined version of the ESTRAMET enzyme immunoassay to determine the EMR of $2 \mathrm{OHE} 1 / 16 \alpha \mathrm{OHE} 1$ validated against a gas chromatography/ mass spectrometry (MS) method. This assay could more sensitively detect estrogen metabolites in the lower postmenopausal range than the first version. ${ }^{68}$ However, a recent study rated reliability of urinary estrogen metabolite determination of postmenopausal women by this enzyme immunoassay problematic compared with a new technique involving liquid chromatography (LC)-MS/MS. ${ }^{69}$ Studies of postmenopausal women reported higher between-assay coefficients of variation than those of premenopausal women. Serum and plasma measurements are even more susceptible to errors because of the lower metabolite concentrations. Further, variation within and between studies may have resulted from differing specimens' sampling patterns, storage length, and time between sampling and diagnoses in prospective studies.

\section{Findings that oppose the postulated hypothesis}

Well-established risk factors for breast cancer that are considered to be related to estrogen exposure, eg, family history, age at menarche, and benign breast disease, ${ }^{38}$ were not substantially or even inversely associated to the EMR, ie, a lower EMR with higher parity, ${ }^{38}$ lower age at first birth, ${ }^{58}$ and high breast density, ${ }^{70}$ respectively. Furthermore, ethnic differences in the EMR do not correspond to breast cancer incidence patterns in Asians and Caucasians. Differences in breast cancer risk between Asians and African Americans were found to be better explained by urinary estradiol, E1, and estriol than by EMR in a cross-sectional study of healthy, nonestrogen-using women. ${ }^{71}$ 


\section{Recommendations for future studies}

Interrelationship of urinary, circulating,

and tissue EMR

Urinary and circulating estrogen metabolites may not be representative of target tissue concentrations of unconjugated metabolites. A recent study of nine patients concluded that the urinary EMR is a good approximation for breast tissue EMR. ${ }^{72}$ This result needs to be confirmed in women without breast cancer. Moreover, differences in median EMR of serum/plasma and urine samples raise the question of whether risk estimates derived from urinary EMR can be compared with those based on circulating EMR. A single study in young women not using oral contraceptives found fair correlation coefficients between urinary and plasma EMR $\left(r_{\mathrm{s}}=0.60\right.$ in Caucasians). ${ }^{60}$ Hence, further assessment of intraindividual correlations between serum/plasma and urinary EMR both in patients and in healthy individuals is warranted.

\section{Association between EMR and subtypes of breast cancer}

There is now ample evidence of etiologic heterogeneity for breast cancer subtypes. ${ }^{73}$ Therefore, the potential for a differential role of EMR and other estrogen metabolites in subtypes of breast tumors (eg, by ER status, high grade) should be investigated in larger prospective studies with sufficient power.

\section{Measurement of the catecholestrogens 4OHEI/4OHE2}

The 4-hydroxylation of estrogens leading to the potentially carcinogenic catecholestrogens $4 \mathrm{OHE} 1 / 4 \mathrm{OHE} 2$ is positively correlated to 2-hydroxylation and might be negatively correlated to $16 \alpha \mathrm{OHE} 1$, depending on the extent of cross-reactivity of the CYP1A1/A2 pathway. ${ }^{74}$ Studies in breast tissue have gained some insight into the relative and absolute amounts of estrogens and their metabolites. Although a higher EMR has been found in normal breast tissues, ${ }^{75}$ supporting the hypothesized role of $16 \alpha \mathrm{OHE} 1$, the most abundant metabolite in cancer tissues was 4OHE2. A study by Rogan et al ${ }^{76}$ detected significantly higher tissue levels of 4OHE1 but not 16OHE1 in 28 cases compared with 46 controls. Additionally, higher concentrations of quinone conjugates derivatives were found in cancer tissues and interpreted as higher potential for quinones to react with DNA. Finally, in a small study, Gaikwad et a ${ }^{49}$ focused on depurinating DNA adduct formation in relation to catecholestrogen concentration, expressed as a ratio. Higher ratio levels, particularly for $4 \mathrm{OHE}$ conjugates indicating a relatively higher DNA adduct formation, were seen in cases and in a high-risk group than in controls (confirmed in an extended group). ${ }^{77}$ These preliminary findings may advise the future direction of research to include the detection of 4OHE1 and 4OHE2 in epidemiological studies of 2OHE1/16 $\alpha$ OHE1 EMR.

\section{Conclusion}

All of nine properly designed epidemiological studies (six prospective case-control studies and three retrospective studies) failed to show a significant relationship between urinary or circulating EMR (2OHE1/16 $\alpha \mathrm{OHE} 1)$ and breast cancer risk. Although premenopausal studies on urinary EMR have suggested a potentially weak inverse relationship, associations were not significantly different compared with postmenopausal or overall combined studies. Thus, at present, there is no evidence that the EMR can predict breast cancer risk. Larger prospective studies are needed to definitely assess a potential association of EMR with risk of breast cancer and risk by subtype (eg, by ER), adjusting for age, menstrual cycle phase, and ethnicity and menopausal status in cases of mixed study populations. A deeper knowledge of interrelationships between urinary, circulating, and tissue levels of estrogen metabolites would help to integrate studies with respect to target tissue values. The measurement of further estrogen metabolites by new LC-MS/MS methods to provide a more complete profile, particularly of 4-hydroxylated and methylated estrogens, may lead to more promising markers for breast cancer.

\section{Disclosure}

The authors report no conflicts of interest in this work.

\section{References}

1. Key T, Appleby P, Barnes I, Reeves G; Endogenous Hormones and Breast Cancer Collaborative Group. Endogenous sex hormones and breast cancer in postmenopausal women: reanalysis of nine prospective studies. J Natl Cancer Inst. 2002;94(8):606-616.

2. Tamimi RM, Byrne C, Colditz GA, Hankinson SE. Endogenous hormone levels, mammographic density, and subsequent risk of breast cancer in postmenopausal women. J Natl Cancer Inst. 2007; 99(15):1178-1187.

3. Eliassen AH, Missmer SA, Tworoger SS, et al. Endogenous steroid hormone concentrations and risk of breast cancer among premenopausal women. J Natl Cancer Inst. 2006;98(19):1406-1415.

4. Travis RC, Key TJ. Oestrogen exposure and breast cancer risk. Breast Cancer Res. 2003;5(5):239-247.

5. Chen WY. Exogenous and endogenous hormones and breast cancer. Best Pract Res Clin Endocrinol Metab. 2008;22(4):573-585.

6. Kaaks R, Berrino F, Key T, et al. Serum sex steroids in premenopausal women and breast cancer risk within the European Prospective Investigation into Cancer and Nutrition (EPIC). $J$ Natl Cancer Inst. 2005;97(10):755-765. 
7. Telang NT, Katdare M, Bradlow HL, Osborne MP. Estradiol metabolism: an endocrine biomarker for modulation of human mammary carcinogenesis. Environ Health Perspect. 1997;105 Suppl 3:559-564.

8. Gupta M, McDougal A, Safe S. Estrogenic and antiestrogenic activities of 16alpha- and 2-hydroxy metabolites of 17 beta-estradiol in MCF-7 and T47D human breast cancer cells. J Steroid Biochem Mol Biol. 1998; 67(5-6):413-419.

9. Li G, Sepkovic DW, Bradlow HL, Telang NT, Wong GY. Lycium barbarum inhibits growth of estrogen receptor positive human breast cancer cells by favorably altering estradiol metabolism. Nutr Cancer. 2009;61(3):408-414.

10. Bradlow HL, Telang NT, Sepkovic DW, Osborne MP. 2-hydroxyestrone: the 'good' estrogen. J Endocrinol. 1996;150 Suppl:S259-S265.

11. Bradlow HL, Hershcopf RJ, Martucci CP, Fishman J. Estradiol 16 alpha-hydroxylation in the mouse correlates with mammary tumor incidence and presence of murine mammary tumor virus: a possible model for the hormonal etiology of breast cancer in humans. Proc Natl Acad Sci U S A. 1985;82(18):6295-6299.

12. Suto A, Bradlow HL, Wong GY, Osborne MP, Telang NT. Experimental down-regulation of intermediate biomarkers of carcinogenesis in mouse mammary epithelial cells. Breast Cancer Res Treat. 1993; 27(3):193-202.

13. Fishman J, Schneider J, Hershcope RJ, Bradlow HL. Increased estrogen-16 alpha-hydroxylase activity in women with breast and endometrial cancer. J Steroid Biochem. 1984;20(4B):1077-1081.

14. Schneider J, Kinne D, Fracchia A, et al. Abnormal oxidative metabolism of estradiol in women with breast cancer. Proc Natl Acad Sci U S A 1982;79(9):3047-3051.

15. Osborne MP, Bradlow HL, Wong GY, Telang NT. Upregulation of estradiol C16 alpha-hydroxylation in human breast tissue: a potential biomarker of breast cancer risk. J Natl Cancer Inst. 1993; 85(23):1917-1920

16. Ho GH, Luo XW, Ji CY, Foo SC, Ng EH. Urinary 2/16 alphahydroxyestrone ratio: correlation with serum insulin-like growth factor binding protein-3 and a potential biomarker of breast cancer risk. Ann Acad Med Singapore. 1998;27(2):294-299.

17. Kabat GC, Chang CJ, Sparano JA, et al. Urinary estrogen metabolites and breast cancer: a case-control study. Cancer Epidemiol Biomarkers Prev. 1997;6(7):505-509.

18. Zheng W, Dunning L, Jin F, Holtzman J. Correspondence re: Kabat GC, et al. Urinary estrogen metabolites and breast cancer: a case-control study. Cancer Epidemiol Biomark Prev. 1997;6:505-509. Cancer Epidemiol Biomarkers Prev. 1998;7(1):85-86.

19. Cavalieri E, Chakravarti D, Guttenplan J, et al. Catechol estrogen quinones as initiators of breast and other human cancers: implications for biomarkers of susceptibility and cancer prevention. Biochim Biophys Acta. 2006;1766(1):63-78.

20. Cavalieri EL, Rogan EG. Depurinating estrogen-DNA adducts in the etiology and prevention of breast and other human cancers. Future Oncol. 2010;6(1):75-91.

21. Fernandez SV, Russo IH, Russo J. Estradiol and its metabolites 4-hydroxyestradiol and 2-hydroxyestradiol induce mutations in human breast epithelial cells. Int J Cancer. 2006;118(8):1862-1868.

22. Liehr JG, Fang WF, Sirbasku DA, Ari-Ulubelen A. Carcinogenicity of catechol estrogens in Syrian hamsters. J Steroid Biochem. 1986; 24(1):353-356.

23. Guillemette C, Bélanger A, Lépine J. Metabolic inactivation of estrogens in breast tissue by UDP-glucuronosyltransferase enzymes: an overview. Breast Cancer Res. 2004;6(6):246-254.

24. Cribb AE, Knight MJ, Dryer D, et al. Role of polymorphic human cytochrome P450 enzymes in estrone oxidation. Cancer Epidemiol Biomarkers Prev. 2006;15(3):551-558.

25. Lee AJ, Cai MX, Thomas PE, Conney AH, Zhu BT. Characterization of the oxidative metabolites of 17 beta-estradiol and estrone formed by 15 selectively expressed human cytochrome p450 isoforms. Endocrinology. 2003;144(8):3382-3398.
26. Paracchini V, Raimondi S, Gram IT, et al. Meta- and pooled analyses of the cytochrome P-450 1B1 Val432 Leu polymorphism and breast cancer: a HuGE-GSEC review. Am J Epidemiol. 2007;165(2):115-125.

27. Paracchini V, Pedotti P, Raimondi S, et al. A common CYP1B1 polymorphism is associated with 2-OHE1/16-OHE1 urinary estrone ratio. Clin Chem Lab Med. 2005;43(7):702-706.

28. Greenlee H, Chen Y, Kabat GC, et al. Variants in estrogen metabolism and biosynthesis genes and urinary estrogen metabolites in women with a family history of breast cancer. Breast Cancer Res Treat. 2007; 102(1):111-117.

29. Tworoger SS, Chubak J, Aiello EJ, et al. Association of CYP17, CYP19, CYP1B1, and COMT polymorphisms with serum and urinary sex hormone concentrations in postmenopausal women. Cancer Epidemiol Biomarkers Prev. 2004;13(1):94-101.

30. Pasagian-Macaulay A, Meilahn EN, Bradlow HL, et al. Urinary markers of estrogen metabolism 2- and 16 alpha-hydroxylation in premenopausal women. Steroids. 1996;61(8):461-467.

31. Westerlind KC, Gibson KJ, Wolfe P. The effect of diurnal and menstrual cyclicity and menopausal status on estrogen metabolites: implications for disease-risk assessment. Steroids. 1999;64(3):233-243.

32. Dallal C, Taioli E. Urinary $2 / 16$ estrogen metabolite ratio levels in healthy women: a review of the literature. Mutat Res. 2010;705(2):154-162.

33. Meilahn EN, de Stavola B, Allen DS, et al. Do urinary oestrogen metabolites predict breast cancer? Guernsey III cohort follow-up. Br J Cancer. 1998;78(9):1250-1255.

34. Bradlow HL, Sepkovic DW, Klug T, Osborne MP. Application of an improved ELISA assay to the analysis of urinary estrogen metabolites. Steroids. 1998;63(7-8):406-413.

35. Klug TL, Bradlow HL, Sepkovic DW. Monoclonal antibody-based enzyme immunoassay for simultaneous quantitation of 2- and 16 alpha-hydroxyestrone in urine. Steroids. 1994;59(11):648-655.

36. Muti P, Bradlow HL, Micheli A, et al. Estrogen metabolism and risk of breast cancer: a prospective study of the 2:16alpha-hydroxyestrone ratio in premenopausal and postmenopausal women. Epidemiology. 2000;11(6):635-640.

37. DerSimonian R, Laird N. Meta-analysis in clinical trials. Control Clin Trials. 1986;7(3):177-188.

38. Arslan AA, Shore RE, Afanasyeva Y, Koenig KL, Toniolo P, Zeleniuch-Jacquotte A. Circulating estrogen metabolites and risk for breast cancer in premenopausal women. Cancer Epidemiol Biomarkers Prev. 2009;18(8):2273-2279.

39. Ursin G, London S, Stanczyk FZ, et al. Urinary 2-hydroxyestrone/16alphahydroxyestrone ratio and risk of breast cancer in postmenopausal women. J Natl Cancer Inst. 1999;91(12):1067-1072.

40. Cauley JA, Zmuda JM, Danielson ME, et al. Estrogen metabolites and the risk of breast cancer in older women. Epidemiology. 2003; 14(6):740-744.

41. Wellejus A, Olsen A, Tjonneland A, Thomsen BL, Overvad K, Loft S. Urinary hydroxyestrogens and breast cancer risk among postmenopausal women: a prospective study. Cancer Epidemiol Biomarkers Prev. 2005; 14(9):2137-2142.

42. Eliassen AH, Missmer SA, Tworoger SS, Hankinson SE. Circulating 2-hydroxy- and 16alpha-hydroxy estrone levels and risk of breast cancer among postmenopausal women. Cancer Epidemiol Biomarkers Prev. 2008;17(8):2029-2035.

43. Kabat GC, O'Leary ES, Gammon MD, et al. Estrogen metabolism and breast cancer. Epidemiology. 2006;17(1):80-88.

44. Fowke JH, Qi D, Bradlow HL, et al. Urinary estrogen metabolites and breast cancer: differential pattern of risk found with pre- versus post-treatment collection. Steroids. 2003;68(1):65-72.

45. Coker AL, Crane MM, Sticca RP, Sepkovic DW. Re: Ethnic differences in estrogen metabolism in healthy women. J Natl Cancer Inst. 1997; 89(1):89-90.

46. Im A, Vogel VG, Ahrendt G, et al. Urinary estrogen metabolites in women at high risk for breast cancer. Carcinogenesis. 2009; 30(9):1532-1535. 
47. Modugno F, Kip KE, Cochrane B, et al. Obesity, hormone therapy, estrogen metabolism and risk of postmenopausal breast cancer. Int $J$ Cancer. 2006;118(5):1292-1301.

48. Adlercreutz H, Fotsis T, Höckerstedt K, et al. Diet and urinary estrogen profile in premenopausal omnivorous and vegetarian women and in premenopausal women with breast cancer. J Steroid Biochem. 1989; 34(1-6):527-530.

49. Gaikwad NW, Yang L, Muti P, et al. The molecular etiology of breast cancer: evidence from biomarkers of risk. Int J Cancer. 2008; 122(9):1949-1957.

50. Alvarez-Vasquez RB, Axelrod D, Frenkel K, et al. Influence of postmenopausal hormone replacement therapy on an estrogen metabolite biomarker of risk for breast cancer. Horm Metab Res. 2003; 35(6):358-361.

51. Bradlow HL, Hershcopf R, Martucci C, Fishman J. 16 alphahydroxylation of estradiol: a possible risk marker for breast cancer. Ann NY Acad Sci. 1986;464:138-151.

52. Garcia-Closas M, Hankinson SE, Ho S, et al. Factors critical to the design and execution of epidemiologic studies and description of an innovative technology to follow the progression from normal to cancer tissue. J Natl Cancer Inst Monogr. 2000;2000(27):147-156.

53. Xu X, Duncan AM, Merz-Demlow BE, Phipps WR, Kurzer MS. Menstrual cycle effects on urinary estrogen metabolites. J Clin Endocrinol Metab. 1999;84(11):3914-3918.

54. Fowke JH, Shu XO, Dai Q, et al. Oral contraceptive use and breast cancer risk: modification by $\mathrm{NAD}(\mathrm{P}) \mathrm{H}$ :quinone oxoreductase (NQO1) genetic polymorphisms. Cancer Epidemiol Biomarkers Prev. 2004; 13(8):1308-1315.

55. Jernström H, Klug TL, Sepkovic DW, Bradlow HL, Narod SA. Predictors of the plasma ratio of 2-hydroxyestrone to 16alpha-hydroxyestrone among pre-menopausal, nulliparous women from four ethnic groups. Carcinogenesis. 2003;24(5):991-1005.

56. Konovalova V, Smetnik V. Impact of hormone replacement therapy on endogenous estradiol hydroxymetabolism in Russian postmenopausal women. Maturitas. 2009;63 Suppl 1:S49.

57. Martini MC, Dancisak BB, Haggans CJ, Thomas W, Slavin JL. Effects of soy intake on sex hormone metabolism in premenopausal women. Nutr Cancer. 1999;34(2):133-139.

58. Falk RT, Fears TR, Xu X, et al. Urinary estrogen metabolites and their ratio among Asian American women. Cancer Epidemiol Biomarkers Prev. 2005;14(1):221-226.

59. Ursin G, London S, Yang D, et al. Urinary 2-hydroxyestrone/16alphahydroxyestrone ratio and family history of breast cancer in premenopausal women. Breast Cancer Res Treat. 2002;72(2):139-143.

60. Bradlow HL, Jernström H, Sepkovic DW, Klug TL, Narod SA. Comparison of plasma and urinary levels of 2-hydroxyestrogen and 16 alpha-hydroxyestrogen metabolites. Mol Genet Metab. 2006; 87(2):135-146.

61. Adlercreutz H, Gorbach SL, Goldin BR, Woods MN, Dwyer JT, Hämäläinen E. Estrogen metabolism and excretion in Oriental and Caucasian women. J Natl Cancer Inst. 1994;86(14):1076-1082.

62. Taioli E, Garte SJ, Trachman J, et al. Ethnic differences in estrogen metabolism in healthy women. J Natl Cancer Inst. 1996;88(9):617.
63. Wacker M, Risendal B, Westerlind K, Lezotte D, Byers T. Ethnicity, body size, and estrogen levels in postmenopausal Hispanic and non-Hispanic white women. J Womens Health (Larchmt). 2009;18(4):487-491.

64. Sowers MR, Crawford S, McConnell DS, et al. Selected diet and lifestyle factors are associated with estrogen metabolites in a multiracial/ethnic population of women. J Nutr. 2006;136(6):1588-1595.

65. Mitrunen K, Hirvonen A. Molecular epidemiology of sporadic breast cancer. The role of polymorphic genes involved in oestrogen biosynthesis and metabolism. Mutat Res. 2003;544(1):9-41.

66. Chen Z, Zheng W, Dunning LM, Anderson KG, Parrish RS, Holtzman JL. Within-person variability of the ratios of urinary 2-hydroxyestrone to 16alpha-hydroxyestrone in Caucasian women. Steroids. 1999;64(12):856-859.

67. Michaud DS, Manson JE, Spiegelman D, et al. Reproducibility of plasma and urinary sex hormone levels in premenopausal women over a one-year period. Cancer Epidemiol Biomarkers Prev. 1999; 8(12):1059-1064

68. Ziegler RG, Rossi SC, Fears TR, et al. Quantifying estrogen metabolism: an evaluation of the reproducibility and validity of enzyme immunoassays for 2-hydroxyestrone and 16alpha-hydroxyestrone in urine. Environ Health Perspect. 1997;105 Suppl 3:607-614.

69. Faupel-Badger JM, Fuhrman BJ, Xu X, et al. Comparison of liquid chromatography-tandem mass spectrometry, RIA, and ELISA methods for measurement of urinary estrogens. Cancer Epidemiol Biomarkers Prev. 2010;19(1):292-300.

70. Riza E, dos Santos Silva I, de Stavola B, et al. Urinary estrogen metabolites and mammographic parenchymal patterns in postmenopausal women. Cancer Epidemiol Biomarkers Prev. 2001;10(6):627-634.

71. Ursin G, Wilson M, Henderson BE, et al. Do urinary estrogen metabolites reflect the differences in breast cancer risk between Singapore Chinese and United States African-American and white women? Cancer Res. 2001;61(8):3326-3329.

72. Taioli E, Im A, Xu X, Veenstra TD, Ahrendt G, Garte S. Comparison of estrogens and estrogen metabolites in human breast tissue and urine. Reprod Biol Endocrinol. 2010;8:93.

73. Althuis MD, Fergenbaum JH, Garcia-Closas M, Brinton LA, Madigan MP, Sherman ME. Etiology of hormone receptor-defined breast cancer: a systematic review of the literature. Cancer Epidemiol Biomarkers Prev. 2004;13(10):1558-1568.

74. Fuhrman BJ, Pfeiffer R, Xu X, et al. Soy intake is associated with increased 2-hydroxylation and decreased 16alpha-hydroxylation of estrogens in Asian-American women. Cancer Epidemiol Biomarkers Prev. 2009; 18(10):2751-2760.

75. Castagnetta LA, Granata OM, Traina A, et al. Tissue content of hydroxyestrogens in relation to survival of breast cancer patients. Clin Cancer Res. 2002;8(10):3146-3155.

76. Rogan EG, Badawi AF, Devanesan PD, et al. Relative imbalances in estrogen metabolism and conjugation in breast tissue of women with carcinoma: potential biomarkers of susceptibility to cancer. Carcinogenesis. 2003;24(4):697-702.

77. Gaikwad NW, Yang L, Pruthi S, et al. Urine biomarkers of risk in the molecular etiology of breast cancer. Breast Cancer Basic Clin Res. 2009;3(1):1-8. 


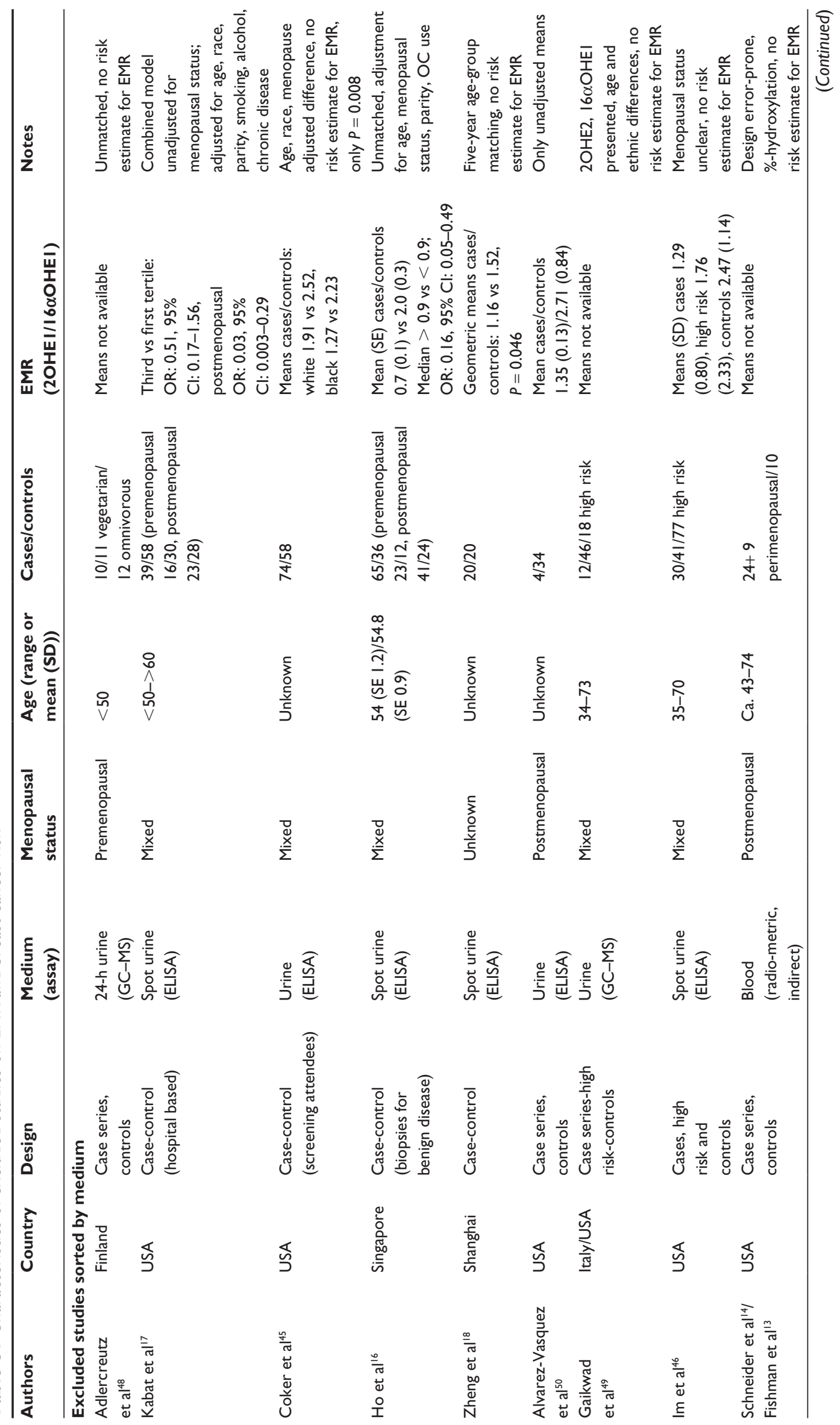




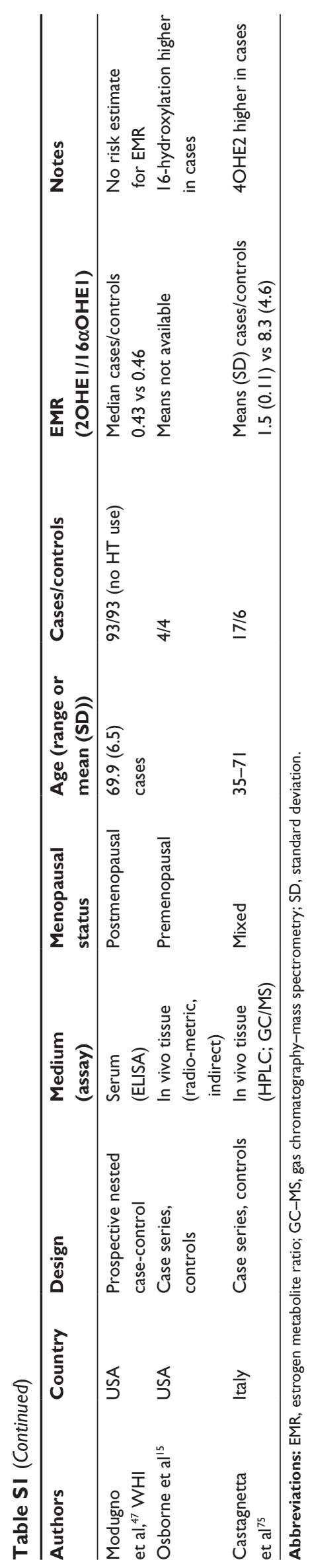


International Journal of Women's Health

Dovepress

\section{Publish your work in this journal}

The International Journal of Women's Health is an international, peerreviewed open-access journal publishing original research, reports, reviews and commentaries on all aspects of women's healthcare including gynecology, obstetrics, and breast cancer. Subject areas include: Chronic conditions (migraine headaches, arthritis, osteoporosis);

Submit your manuscript here: http://www.dovepress.com/international-journal-of-womens-health-journa
Endocrine and autoimmune syndromes; Sexual and reproductive health; Psychological and psychosocial conditions. The manuscript management system is completely online and includes a very quick and fair peer-review system. Visit http://www.dovepress.com/ testimonials.php to read real quotes from published authors. 